\title{
Small Intestinal Follicular Lymphoma
}

National Cancer Institute

\section{Source}

National Cancer Institute. Small Intestinal Follicular Lymphoma. NCI Thesaurus. Code C96056.

A follicular lymphoma that arises from the small intestine. It most often affects the duodenum. 